\title{
The HIV-1 vpr protein induces anoikis-resistance by modulating cell adhesion process and microfilament system assembly
}

\author{
P Matarrese ${ }^{1}$, L Conti ${ }^{2}$, B Varano ${ }^{2}$, MC Gauzzi $^{2}$, F Belardelli ${ }^{2}$, \\ S Gessani ${ }^{2}$ and W Malorni ${ }^{*, 1}$ \\ 1 Department of Ultrastructures, Instituto Superiore di Sanità, Viale Regina \\ Elena, 299-00161 Rome, Italy \\ 2 Department of Virology, Instituto Superiore di Sanità, Viale Regina Elena, 299- \\ 00161 Rome, Italy \\ * Corresponding author: W Malorni, Dept. of Ultrastructures, Instituto Superiore \\ di Sanità, V.le Regina Elena, 29900161 Rome, Italy. Tel: ++39 06 49902905; \\ Fax: ++39 06 49387140; E-mail: Malorni@mclink.it
}

Received 27.7.99; revised 29.9.99; accepted 18.10.99

Edited by ML Gougeon

\begin{abstract}
We have previously shown that $\mathrm{CD}^{+} \mathrm{T}$ Jurkat cells constitutively expressing low levels of the human immunodeficiency virus 1 (HIV-1) vpr protein were less susceptible to undergo apoptosis than control cells. ${ }^{1}$ In this study we have investigated the role of $\mathrm{vpr}$ in affecting mechanisms of importance in the control of apoptosis. Vpr-expressing clones consistently aggregated in clusters with time in culture, whereas mock-transfected cells grew as dispersed cultures. The analysis of adhesion molecules involved in cell-to-cell as well as in cell-substrate interactions showed a higher expression of cadherin and integrins $\alpha 5$ and $\alpha 6$ in vprtransfected clones with respect to mock-transfected cells. This up-modulation was specifically blocked by cell exposure to antisense oligonucleotides targeted at the vpr. In addition, F-actin microfilament cytoskeletal organization, known to be involved in cell-cell interaction pathways and in the modulation of cell surface molecule expression, was significantly improved in vpr-expressing clones, in which filament polymerization was increased. We thus envisage that vpr viral protein can maintain cell survival via a specific activity on cytoskeleton-dependent cell adhesion pathways, i.e. by inducing anoikis-resistance. These particular effects of vpr might enhance the homing, spreading and survival of the infected lymphocytes, thus contributing to virus persistence in the course of acute HIV-1 infection. Cell Death and Differentiation (2000) 7, 25-36.
\end{abstract}

Keywords: HIV-1; vpr; apoptosis; adhesion molecules; anoikia; cytoskeleton

Abbreviations: HIV-1, human immunodeficiency virus 1; SIV, simian immunodeficiency virus; FCS, foetal calf serum; AO, antisense phosphorothioate oligodeoxynucleotides; SO, sense phosphorothioate oligodeoxynucleotides; $\mathrm{CHX}$, cycloheximide; TNF- $\alpha$, tumor necrosis factor- $\alpha$; EDTA, ethylenediamine tetraacetate; PBS, phosphate buffered saline; BSA, bovine serum albumin; SEM, scanning electron microscopy; ECM, extra cellular matrix

\section{Introduction}

The vpr accessory gene encodes a small basic protein of approximately 96 amino acids that is highly conserved in HIV1 , HIV-2 and simian immunodeficiency virus (SIV). Vpr is the only accessory protein packaged into viral particles in significant amounts through an interaction with the p6 domain of the p55 Gag protein. ${ }^{2,3}$ The incorporation of vpr into viral progeny is highly suggestive of its participation in early events of viral infection. In this regard, functions ascribed to vpr include transport of the viral core into the nucleus of non dividing cells and up-regulation of viral genes expression. More recently, other intriguing functions of vpr have been described. In particular, it has been shown that vpr can regulate cell cycle progression and apoptosis. ${ }^{1,4-6}$ These results suggested that vpr can directly or indirectly interact with regulation pathways involved in the control of cell proliferation and survival.

Apoptosis is a regulated process of cell suicide, essential for normal development and homeostasis in multicellular organisms, which has important roles in both non infectious and infectious diseases. Several lines of evidence suggest that most eukariotic cells respond to viral disruption of cellular homeostasis by undergoing apoptosis. ${ }^{6}$ To counteract this, many viruses have evolved mechanisms to block host cell death. In some cases, viral genomes have been found to possess genes whose products are capable of modulating, either positively or negatively, apoptosis of their host cells. ${ }^{6}$ With respect to HIV-1, it has been recently demonstrated that the low levels of the accessory protein vpr can act as a negative regulator of the apoptotic response induced by different stimuli. ${ }^{1,4,7}$ In this regard, we have reported the establishment of vpr transfectants that stably express low levels of vpr protein and exhibit a reduced capability to undergo apoptosis in response to different stimuli. ${ }^{1}$

In the present work, we have further characterized the phenotype of our Jurkat clones expressing vpr, especially in regard to cellular and molecular changes potentially important in affecting cell adhesion properties, homing and persistence of HIV-infected cells. Cell-to-cell and cell-matrix interactions play a pivotal role in numerous cell functions, including gene regulation, cytoskeletal assembly and cell locomotion, differentiation, homing and growth control. In particular, recent data have indicated that the extra-cellular 
matrix can act as a survival factor for many cell types. ${ }^{8}$ These observations strongly suggested that lack of matrix attachment can stringently restrict inappropriate cell growth by inducing apoptosis. ${ }^{9}$ The expression at the cell surface of a plethora of molecules, including cell adhesion molecules, appears to be regulated by certain cytoskeletal element integrity and function. ${ }^{9,10}$ In particular, the microfilament system has been implicated in the regulation of cell surface expression of a number of molecules, e.g., integrins and immunoglobulin-like molecules, which need to be modulated depending on cell activity. ${ }^{11}$ Furthermore, alteration of cytoskeleton integrity has also been shown to influence the apoptotic process. ${ }^{12}$ Interestingly, the latter could be a consequence of changes in surface molecules expression. $^{13}$

We report herein that vpr expression in Jurkat cells results in a remarkable modification of cell-to-cell and cellto-substrate interactions, possibly by specifically up-regulating the expression of certain adhesion molecules (i.e., cadherin and integrins $\alpha 5$ and $\alpha 6$ ) and by affecting the cytoskeleton system. We suggest that these vpr-induced changes are important in rendering the cells resistant to apoptosis and, in the course of a natural infection, in favoring the homing of the infected cells to lymphoid tissues, thus allowing HIV-1 persistence and subsequent virus spread at later stages of the disease.

\section{Results \\ Effect of the constitutive expression of vpr on the morphology and growth features of Jurkat cells}

To elucidate the mechanism(s) underlying the different susceptibility to apoptosis of vpr-expressing clones with respect to mock-transfected cells, ${ }^{1}$ qualitative and quantitative analyses have been first carried out to further characterize the phenotype of different clones. Although we consistently failed to detect any alteration in the cell cycle progression of vpr-expressing cells, ${ }^{1}$ remarkable differences in the cell growth features were observed by light and scanning electron microscopy analyses in vprexpressing clones with respect to control cells. In particular, while both parental Jurkat cells (not shown) and mocktransfected clones (Figure 1a) grew as dispersed cultures, numerous cell clumps were detected in vpr-expressing clones (arrows, Figure 1b). Clumps were formed by a variable number of cells and appeared as large clusters flowing freely in the culture medium. It is important to note that these aggregates did not lead to syncytia formation through plasma membrane fusion process, as instead observed in HIV-1 infected cells both in vitro and in vivo. As shown in Figure 1c, the growth features exhibited by vpr transfectants were completely reverted to those of control cells when these cultures were maintained in the continuous presence $(72 \mathrm{~h})$ of $\mathrm{AO}$. Moreover, parallel modifications of cell-cell interactions were observed in vpr-expressing clones. In particular, when scanning electron microscopy (SEM) analyses were performed, vpr transfectants appeared as clumps of cells growing intertwined to form cell aggregates (compare pictures (d) and (e) in Figure 1 which represent control and vpr-expressing cells, respectively). A representative example of cell-cell interaction ultrastructural features of control and vpr-expressing cells is also shown at higher magnification in Figure 1f,g. Vpr-transfected cells show close cell-cell relationships due to strict intertwining of microvillous structures (Figure 1g). Similar cell growth features and ultrastructural characteristics have also been observed in other vpr-expressing clones (data not shown). A quantitative analysis of the phenomenon of cell-aggregation was performed as stated in Materials and Methods. Considering the number of clusters formed by at least ten cells, a highly significant difference $(P<0.001)$ was found between mock-transfected cells (mean of three different clones) and vpr-expressing cells (mean of four different clones) (Figure 2a). However, the size of clusters observed in cultured clones appeared etherogeneous: small as well as very large clusters were in fact observable in vprexpressing cell cultures (from isolated cells up to aggregates of more than 50 cells). Thus, taking into consideration the fact that small aggregates were occasionally found in control cells, the extent of this phenomenon was quantified by arbitrarily classifying clusters in eight different classes. The distribution into these classes was significantly different $(P<0.001)$ in control cells with respect to vpr-expressing cells (Figure $2 \mathrm{~b}$ and $\mathrm{c}$, respectively). Notably, large cell aggregates formed by more than 20 cells were only found in vpr-expressing clones (Figure 2c). Cluster formation in vpr-expressing cells was completely abolished when these cultures were maintained in the continuous presence of vpr AO (Figure 2a, hatched bar and Figure 2d). No effect was observed in the presence of control SO (data not shown). Likewise, the addition of either $\mathrm{SO}$ or AO to control cultures did not result in any change in their growth features (data not shown).

\section{Effect of the vpr protein on the expression of adhesion molecules in Jurkat cells}

We then carried out experiments aimed at evaluating whether the different growth features of vpr-expressing cells could be related to some modification in the expression of molecules involved in cell adhesion processes. In particular, we focused our attention on adhesion molecules involved in both heterotypic (cell-substrate) and homotypic (cell-to-cell) interactions. In a first set of experiments, the expression of a panel of molecules was comparatively analyzed in various mockand vpr-transfected clones. In particular, the expression of integrins such as $\alpha 1$ (collagen receptor), $\alpha 2$ (collagen receptor), $\alpha 3$ (lamin, collagen and fibronectin receptor), $\alpha 4$ (receptor for fibronectin and VCAM-1), $\alpha 5$ (fibronectin receptor), $\alpha 6$ (laminin receptor), $\alpha \mathrm{v}$ (vitronectin, fibronectin and collagen receptor), $\beta 1$ (receptor of various extracellular matrix proteins as a heterodimer associated with $\alpha$ subunits), immunoglobulin-like molecule CD44 (hyaluronic acid receptor) and CD54 (also termed ICAM-1, LFA-1 ligand) was evaluated. A well-known protein involved in homotypic contacts, such as cadherin, has also been considered. The results obtained are summarized in Table 1 . The surface expression of $\alpha 5$ and $\alpha 6$ integrins, as well as of cadherin, appeared to be significantly increased in vpr-expressing cells 
with respect to control cells $(P<0.001)$. In fact, comparative analysis of a representative mock-transfected clone (CMV2) versus a representative vpr-expressing one (vpr4) gave the following values: $\alpha 5 \Delta=+38.6 \%$; $\alpha 6 \Delta=+42.4 \%$; cadherin $\Delta=$ $+52.2 \%$. Data reported in Table 1 are referred to CMV3, vpr4 and vpr10 clones but, more in general, mean values obtained from four vpr-expressing clones (vpr4, vpr7, vpr9 and vpr10) were significantly higher $(P<0.001)$ than those found in the control clones (CMV2, CMV3 and CMV5). By contrast, the quantitative expression of other surface molecules (i.e., $\alpha 1$, $\alpha 2, \alpha 3, \alpha 4, \alpha \vee$ nd $\beta 1$ integrins, CD44 and ICAM-1) was not modified in vpr-expressing cells with respect to control cells (Table 1).

We then performed a series of experiments aimed at evaluating whether the alterations in the expression of these adhesion molecules were specifically due to $\mathrm{vpr}$ expression. As shown in Figure 3, culture of vpr-expressing cells in the continuous presence of $\mathrm{AO}$ almost completely reverted the up-regulation of $\alpha 5, \alpha 6$ and cadherin molecules to levels comparable to those of control cells. In particular, the vpr AO treatment (green curves) almost completely

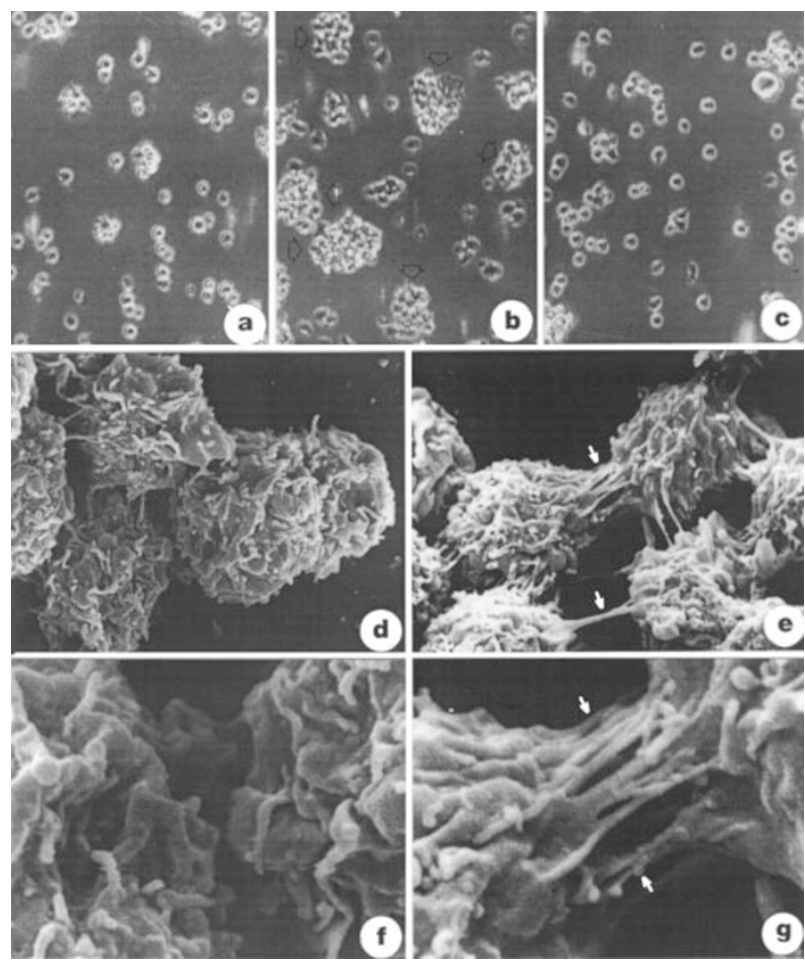

Figure 1 Effect of vpr expression on morphology and cell growth features of Jurkat T cells. Phase contrast microscopy $(\mathbf{a}-\mathbf{c})$ of mock-transfected cells $(\mathbf{a}$, CMV2 clone), vpr-expressing cells (b, vpr4 clone), and vpr-expressing cells cultured for $72 \mathrm{~h}$ in the continuous presence of $A O$ as described in Materials and Methods (c, vpr4 clone). Black arrows in (b) indicate cell clusters. Scanning electron micrographs $(\mathbf{d}-\mathbf{g})$ show at low (d and $\mathbf{e})$ and high (f and $\mathbf{g}$ ) magnification ultrastructural features of mock-transfected (d and $\mathbf{f}$ ) and vprexpressing (e and $\mathbf{g}$ ) cells. Intimate cell-to-cell interactions formed by cell surface protrusions in vpr-expressing cells are noted (right panel). White arrows in (e) and (g) indicate cell-to-cell lamellipodial structures. (a-c), Magnification $800 \times$; (d and e), magnification $6000 \times$; (f and g), magnification $20000 x$
Table 1 Quantitative evaluation of adhesion molecules by flow cytometry analysis

\begin{tabular}{lccc}
\hline $\begin{array}{l}\text { Adhesion } \\
\text { related proteins }\end{array}$ & CMV3 & vpr4 & vpr10 \\
\hline negative & $96 \pm 7$ & $109 \pm 3$ & $99 \pm 6$ \\
alpha-1 & $253 \pm 11$ & $252 \pm 9$ & $257 \pm 8$ \\
alpha-2 & $136 \pm 5$ & $143 \pm 4$ & $147 \pm 5$ \\
alpha-3 & $216 \pm 10$ & $208 \pm 12$ & $220 \pm 7$ \\
alpha-4 & $400 \pm 21$ & $397 \pm 18$ & $384 \pm 14$ \\
alpha-5* & $497 \pm 23$ & $683 \pm 22$ & $681 \pm 24$ \\
alpha-6* & $309 \pm 9$ & $421 \pm 15$ & $433 \pm 11$ \\
alpha-v & $228 \pm 7$ & $234 \pm 5$ & $237 \pm 7$ \\
beta-1 & $593 \pm 24$ & $589 \pm 19$ & $591 \pm 9$ \\
CD44 & $110 \pm 6$ & $108 \pm 9$ & $112 \pm 7$ \\
ICAM-1 & $276 \pm 13$ & $248 \pm 11$ & $254 \pm 10$ \\
cadherin* & $368 \pm 8$ & $555 \pm 19$ & $549 \pm 16$ \\
\hline
\end{tabular}

Numbers reported in the table represent fluorescence emission, expressed as mean of the median values of the histograms obtained from four separate experiments \pm S.D. Calculation of median values was carried out after conversion of logarithmically amplified signals into values on a linear scale. The differences between mock- and vpr-transfected cells are expressed as $\Delta \%$. ( $\left.{ }^{*}\right)$ indicates $P<0.001$ (calculated by using K/S test)
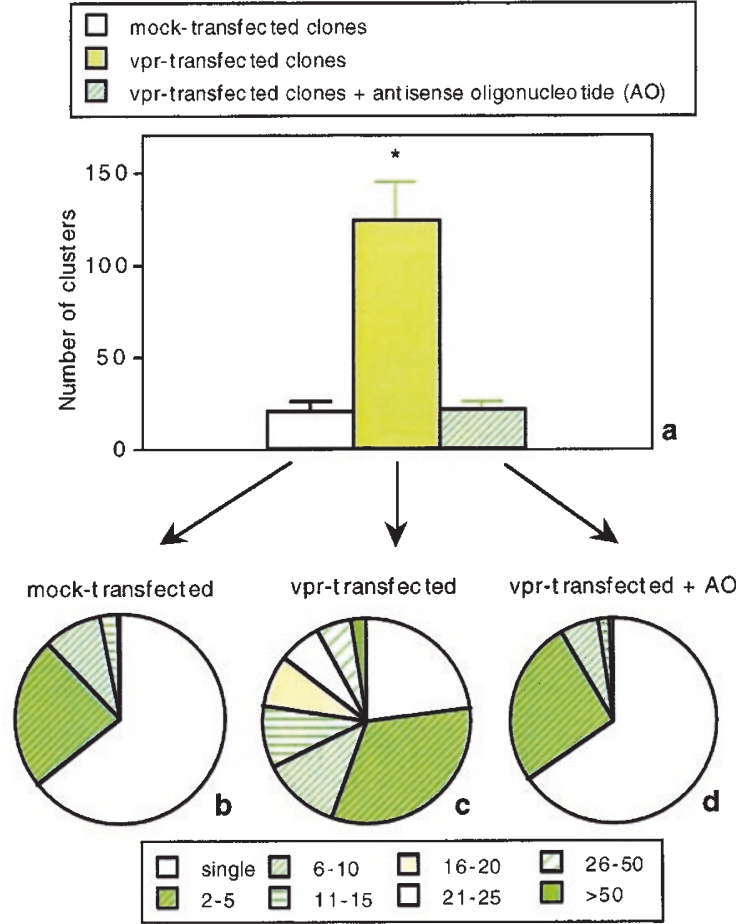

Figure 2 Vpr-mediated induction of cell aggregation (a). Number of clusters formed by at least 10 cells observed in vpr-expressing and mock-transfected clones in the absence or presence of AO targeted at vpr. The values reported are the means \pm S.D. from four (vpr-expressing) and three (mock-transfected) clones. Statistical analyses were performed by Manova test. $\left(^{*}\right)$ in $(a)$ indicate a $P<0.001$ versus mock-transfected cells and versus vpr-expressing cells exposed to vpr AO. Cluster distribution in mock-transfected and vprexpressing clones in absence or presence of $A O(\mathbf{b}-\mathbf{d})$. Eight arbitrarilydefined classes of clusters (from single cells to aggregates of more than 50 cells, see Materials and Methods) are shown. Results obtained by variance analysis indicated: (i) a significant difference $(P<0.001)$ between mocktransfected and vpr-expressing clones; (ii) a significant difference $(P<0.001)$ between vpr-expressing cells and vpr-expressing clones in presence of $\mathrm{AO}$; (iii) no difference $(P>0.05)$ between mock-transfected cells and vprexpressing clones in presence of vpr $\mathrm{AO}$ 
abolished the difference (calculated as $\Delta \%$ ) in the expression of $\alpha 5$ (Figure 3a; $\Delta=-8 \pm 1.3 \%, P>0.05$ ), $\alpha 6$ (Figure $3 b ; \Delta=+0.7 \pm 0.5 \%, P>0.05$ ) and cadherin (Figure 3c; $\Delta=-7.5 \pm 1.3, P>0.05$ ) between control (black curves) and vpr-expressing (gray curves) cells. In contrast, SO treatment (brown curves) did not significantly $(P>0.05)$
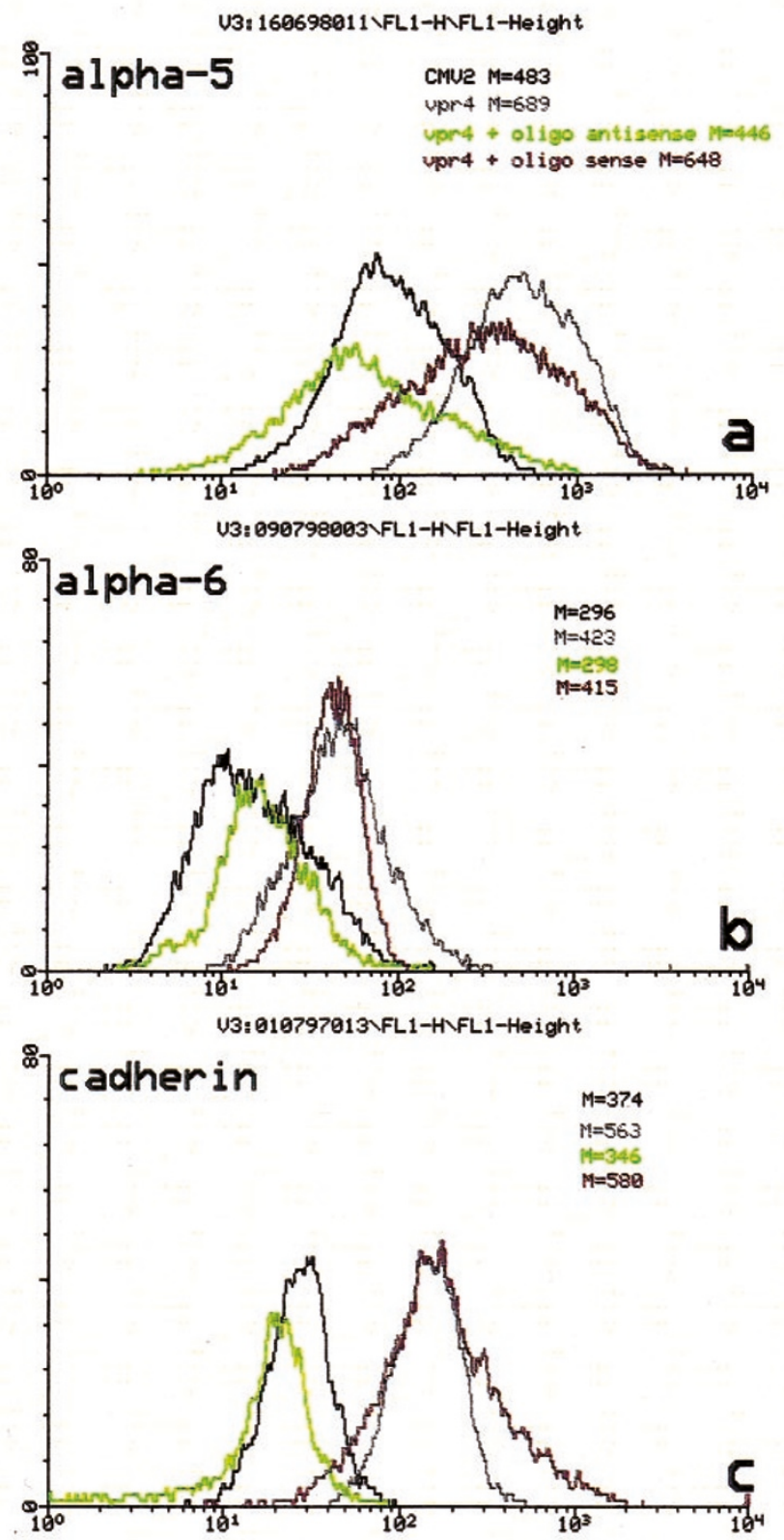

Figure 3 Increased expression of $\alpha 5$ and $\alpha 6$ integrins and cadherin in vprexpressing cells. Flow cytometry analyses of $\alpha 5$ and $\alpha 6$ integrins (a and $\mathbf{b}$, respectively) and cadherin (c) were carried out as described in Materials and Methods under different experimental conditions. Black curves: untreated control cells (CMV2 clone); gray curves: untreated vpr-expressing cells (vpr4 clone); green curves: vpr-expressing cells cultured in the continuous presence of $\mathrm{AO}$; brown curves: vpr-expressing cells cultured in the continuous presence of SO. On the abscissa, FL1 indicates green fluorescence (log scale), the ordinate indicates the relative cell number. One experiment representative of four is shown modify the expression of $\alpha 5, \alpha 6$ and cadherin in vprexpressing cells with respect to controls (Figure 3 ).

In a second series of experiments, we evaluated whether the increased expression of integrins $\alpha 5$ and $\alpha 6$ in $\mathrm{vpr}$ transfectants resulted in some functional modification of their adhesion capability. Thus, we quantitatively evaluated the ability of mock- and vpr-transfected clones to interact with the main extracellular matrix proteins bound by $\alpha 5$ and $\alpha 6$ integrins, i.e. fibronectin and laminin, respectively. The results, reported in Figure 4, pointed to a significant difference between vpr-expressing clones and control Jurkat cells in terms of their adhesion capability. In particular, comparing control cells (three different clones) with vpr-expressing cells (four different clones), we found highly significant differences $(P<0.01)$ in their ability to adhere on laminin coated wells, while there was only a minor increase $(P<0.05)$ in the adhesion to fibronectincoated surfaces. No difference $(P>0.05)$ was found in the adhesion capacity to poly-L-lysine coated wells between mock- and vpr-transfected cells.

\section{Modification of cadherin, $\alpha 5$ and $\alpha 6$ integrins expression in mock- and vpr-transfected clones stimulated to undergo apoptosis}

Previous studies have suggested that some adhesion molecules can play a role in cell survival. ${ }^{9,14}$ In light of these data as well as of our previous study demonstrating that $\mathrm{vpr}$ expression renders cells less susceptible to apoptosis, ${ }^{5}$ we monitored the expression of $\alpha 5, \alpha 6$ and cadherin molecules following stimulation of cells with different apoptotic stimuli. The results of a representative experiment are shown in Figure 5. Quantitative evaluation of the extent of apoptosis, at the time in which the

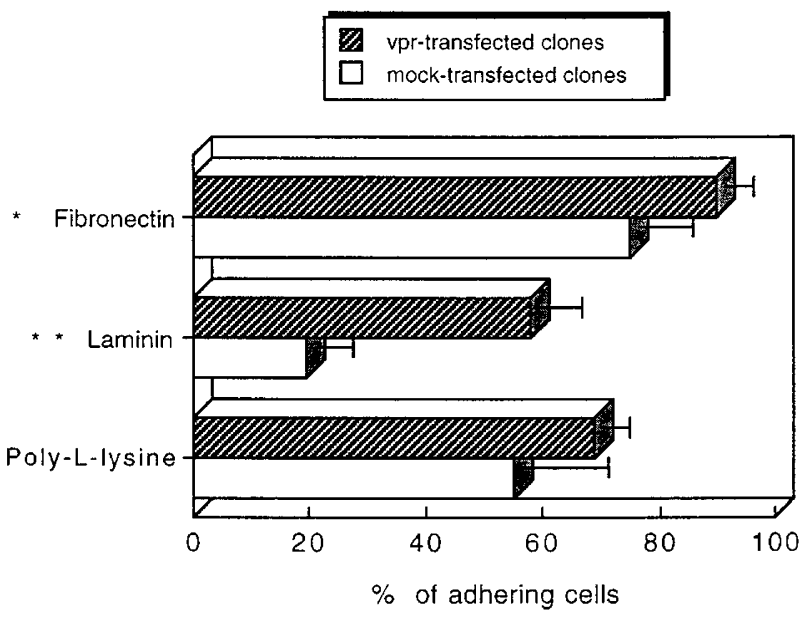

Figure 4 Effect of vpr expression on the adhesion properties of Jurkat cells. Percentage of mock- and vpr-transfected cells adhering on poly-L-lysine, fibronectin and laminin. The values reported are the mean \pm S.D. of four separate experiments performed by using three different mock-transfected and four different vpr-expressing clones. Student's $t$-test to correlate mocktransfected and vpr-expressing clones was used. $\left(^{*}\right)$ indicates $P<0.05 ;\left(^{* *}\right)$ indicates $P<0.01$. No significant difference $(P>0.05)$ was found for poly-Llysine 
expression of adhesion molecules was measured, indicated that the percentage of vpr-expressing cells undergoing apoptosis after Fas triggering was significantly lower
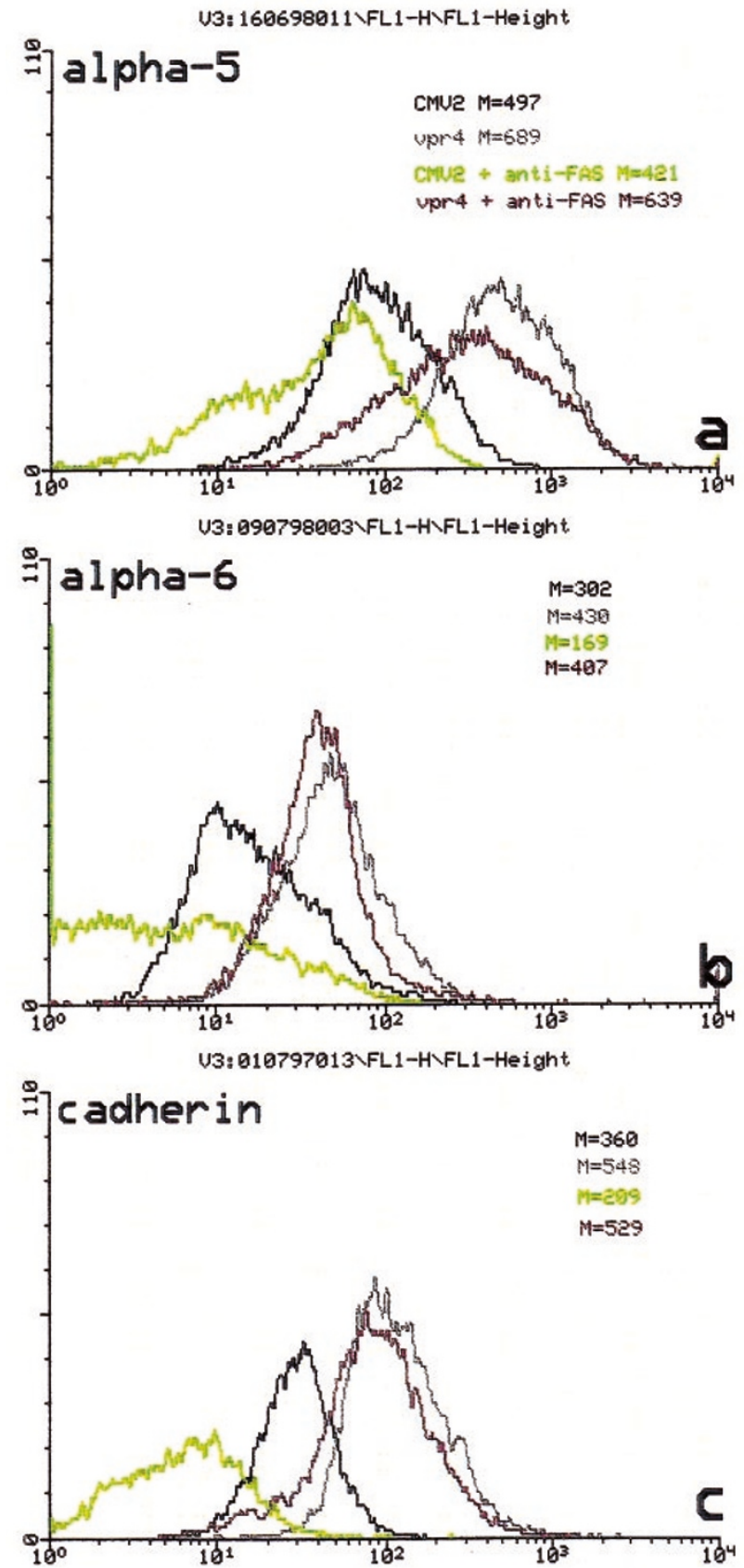

Figure 5 Modification of cadherin, $\alpha 5$ and $\alpha 6$ integrins expression in mockand vpr-transfected clones stimulated to undergo apoptosis. Flow cytometry analysis of $\alpha 5$ and $\alpha 6$ integrins (a and $\mathbf{b}$, respectively) and cadherin (c) was carried out as described in Materials and Methods under different experimental conditions. Black curves: untreated control cells (CMV2 clone); gray curves: untreated vpr-expressing cells (vpr4 clone); green curves: control cells treated with MAb anti-Fas for $4 \mathrm{~h}$; brown curves: vpr-expressing cells treated with MAb anti-Fas for $4 \mathrm{~h}$. On the abscissa, FL1 indicates green fluorescence (log scale), the ordinate indicates the relative cell number. One experiment representative of four is shown
$(31.3 \pm 4 \%)$ with respect to that found in control cells $(75.3 \pm 6.5 \% ; P<0.001)$ while the percentage of spontaneous apoptosis in unstimulated cells was comparable $(1.9 \pm 0.9$ and $2.1 \pm 0.7 \%$, respectively). A significant decrease $(P<0.001)$ in surface expression of $\alpha 5$ and $\alpha 6$ integrins was observed in control cells after induction of apoptosis by Fas triggering (green curves in Figure 5a,b). Note that injured and dead cells, thanks to the red staining due to the loss of plasma membrane integrity and to the consequent presence of $\mathrm{PI}$ into the nucleus, were excluded from the analyses (as specified in Materials and Methods). Interestingly, this reduction in the expression on the cell surface of these molecules was paralleled by a concomitant and significant $(P<0.01)$ increase in their intracellular expression levels ( $\alpha 5: \Delta:+35 \pm 9 \% ; \alpha 6: \Delta:+28 \pm 2 \%)$. By contrast, the surface (Figure $5 a, b)$, as well as the intracellular (data not shown) expression of $\alpha 5$ and $\alpha 6$ integrins remained substantially unmodified in vpr-expressing clones under the same experimental conditions $(P>0.05)$. Hence, as a general rule, following apoptosis induction, cell homeostasis, including the homeostatic balance between cell surface and intracytoplasmic expression of integrins $\alpha 5$ and $\alpha 6$, was maintained in vprexpressing clones but not in control cells. Similarly, a marked reduction in the cadherin expression was found in control cells but not in vpr-expressing clones during apoptosis (Figure 5c). The same results were also obtained after induction of apoptosis by a combined treatment with $\mathrm{CHX} / \mathrm{TNF}-\alpha$ (data not shown).

\section{Effect of vpr expression on cytoskeleton organization}

Establishment of either integrin-mediated heterotypic interactions or cadherin-dependent homotypic cell-to-cell contacts requires an active role of the actin microfilament system compartment. ${ }^{12}$ In addition, actin is directly involved in membrane-cytoplasmic trafficking of signaling molecules. ${ }^{15}$ The dynamic state of actin microfilament network was thus analyzed by flow and static cytometry in control and vpr-expressing cells. The expression and organization of monomeric (G-actin, line 1 in Figure 6$)$, polymeric ( $F$ actin, line 2 in Figure 6$)$ and 'total' actin ( $\mathrm{G}+\mathrm{F}$-actin, line 3 in Figure 6) was evaluated by using DNAse I fluorescent probe, FITC-phalloidin and MAb anti-actin, respectively. Two important changes were mainly appreciable in vprtransfected clones with respect to mock-transfected cells: (i) an evident and significant increase of polymerized $\mathrm{F}$ actin content (Figure 6a, line 2; dashed curve) and (ii) a remarkable rearrangement and improvement of filamentous structures of this protein as detected by confocal microscopy (compare Figure $6 \mathrm{~b}$ and $\mathrm{c}$, line 2). In addition, the statistical analysis of our data indicated that G-actin pool remained unchanged (Figure $6 a-c$, line 1), while an increase of total actin content (Figure 6a-c, line 3) was detected in vpr-expressing clones. In particular, the massive reorganization of polymeric actin in vpr-expressing cells was represented by the formation of long and filamentous structures, namely stress fibers. We then extended these analyses to a panel of cytoskeleton 
proteins involved in the integrity of microfilament system network and regulation of cellular trafficking such as tubulin, $\alpha$-actinin, gelsolin, fodrin, talin, vinculin, ezrin, filamin (Table 2). A significant increase $(P<0.01)$ in vprexpressing cells with respect to control clones was found in the expression of ezrin protein, which is strictly associated with F-actin at the level of the uropods and projecting microspikes, representing a very important molecule in lymphocyte migration.

In light of these effects induced by vpr protein on the cytoskeleton of Jurkat transfected cells we analyzed, both quantitatively (by flow cytometry) and qualitatively (by fluorescence microscopy), various isoforms of proteins belonging to the rho family, i.e. rho $A, B$ and $G$ as well as Rac-1 and Rho GDI (responsible for activation/deactivation cycle of the rho proteins) which are involved in actin filament polymerization and assembly, integrin-mediated cell spreading and cell life and death. ${ }^{16,17}$ Our results, reported in Table 2 (bottom) indicated a significant increase of these proteins, particularly of rho $\mathrm{B}(P<0.01)$, in vpr-expressing cells with respect to control clones. However, the fact that all
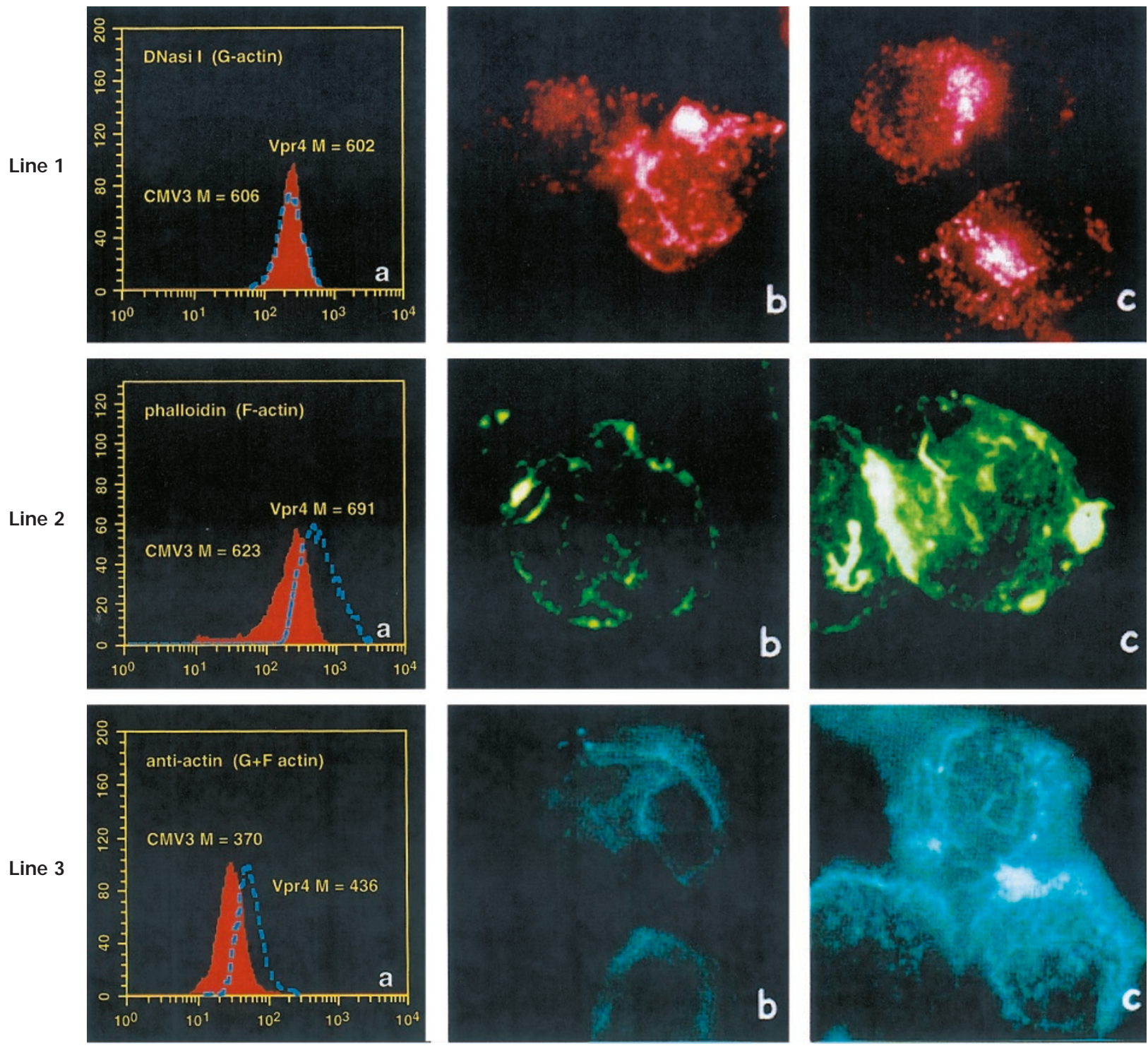

Figure 6 Changes in the actin cytoskeleton organization in vpr-expressing cells. (a) Flow cytometric analysis of the 'polymerization state' of the actin protein in control cells (CMV3, continuous curves) and vpr-expressing cells (vpr4, dashed curves). The shift of dashed curves in panels (a) lines 2 and 3 indicates a significant $(P<0.01)$ increase of polymerized (line 2) and total (line 3) actin in vpr-expressing cells with respect to control clones. As shown line 1 , vpr does not influence the quantitative expression (a) or organization (b and $\mathbf{c}$ ) of monomeric actin. The quantitative increase shown in (a), lines 2 and 3 , corresponds to a profound qualitative modification of microfilament network. Fluorescence micrographs, obtained by confocal laser scanning microscopy, of mock-transfected (b) and vpr-expressing (c) cells stained for $\mathrm{G}$-actin (line 1), F-actin (line 2) and G+F actin (line 3), show a remarkable rearrangement in the assembly of filamentous structures of actin protein in vpr-expressing cells (c, in line 2, F-actin, and in line $3, \mathrm{G}+\mathrm{F}$ actin) as compared to mock-transfected cells (b) in lines 2 and 3 ). Note the filaments and stress fibers detectable only in (c, lines 2 and 3). By contrast, no changes in monomeric actin organization and distribution are observed in vprexpressing cells with respect to control cells (compare $\mathbf{b}$ and $\mathbf{c}$ in line 1). Magnification of pictures $\mathbf{b}$ and $\mathbf{c}$ in lines $1-3: 2000 \times$ 
Table 2 Quantitative evaluation of cytoskeletal components and Rho family proteins by flow cytometry analysis

\begin{tabular}{llll}
\hline $\begin{array}{l}\text { Cytoskeleton } \\
\text { proteins }\end{array}$ & CMV3 & Vpr4 & Vpr10 \\
\hline G-actin & $605 \pm 9$ & $600 \pm 7$ & $603 \pm 7$ \\
F-actin* & $625 \pm 12$ & $690 \pm 10$ & $693 \pm 13$ \\
(G+F)-actin* & $369 \pm 11$ & $437 \pm 9$ & $441 \pm 14$ \\
alpha-actinin & $682 \pm 53$ & $679 \pm 27$ & $690 \pm 31$ \\
gelsolin & $241 \pm 12$ & $235 \pm 15$ & $239 \pm 16$ \\
fodrin & $266 \pm 21$ & $294 \pm 18$ & $287 \pm 15$ \\
talin & $287 \pm 19$ & $279 \pm 21$ & $283 \pm 21$ \\
vinculin & $220 \pm 16$ & $236 \pm 13$ & $215 \pm 20$ \\
ezrin* & $259 \pm 27$ & $301 \pm 23$ & $302 \pm 29$ \\
filamin & $400 \pm 34$ & $422 \pm 33$ & $424 \pm 27$ \\
tubulin & $668 \pm 41$ & $678 \pm 37$ & $673 \pm 39$ \\
Rho family proteins & & & \\
Rho A & $518 \pm 25$ & $520 \pm 28$ & $527 \pm 30$ \\
Rho B* & $363 \pm 19$ & $394 \pm 16$ & $446 \pm 19$ \\
Rho G & $350 \pm 33$ & $380 \pm 31$ & $380 \pm 28$ \\
Rho GDI & $465 \pm 15$ & $472 \pm 17$ & $498 \pm 14$ \\
negative (MAb) & $115 \pm 8$ & $114 \pm 10$ & $110 \pm 12$ \\
negative (PAb) & $113 \pm 11$ & $109 \pm 9$ & $111 \pm 10$ \\
\hline
\end{tabular}

Numbers reported in the table represent fluorescence emission, expressed as mean of the median values of the histograms obtained from four separate experiments \pm S.D. Calculation of median values was carried out after conversion of logarithmically amplified signals into values on a linear scale. The differences between mock- and vpr-transfected cells are expressed as $\Delta \%$. $\left(^{*}\right)$ indicates $P<0.01$. The analyses of proteins belonging to the Rho family, performed by using the Manova test, indicated a significant $(P<0.01)$ difference between control and vpr-expressing clones

the rho family proteins considered here appeared to be increased, was also taken into account. Statistical elaboration of these data, performed by using Manova test, clearly indicated a significant difference $(P<0.01)$ between vpr- and CMV-transfected clones. However, the qualitative analyses of these proteins by immunofluorescence microscopy failed to reveal any significant alteration of their intracellular distribution in vpr expressing cells.

\section{Effects of vpr protein on bcl-2 family proteins intracytoplasmic distribution}

We have previously demonstrated quantitative alterations of the apoptosis-related bcl-2 family molecules in vprtransfected clones. ${ }^{1}$ In consideration of the above reported results and of the importance of cytoskeleton in the movements and activity of bax and $b c l-x_{L}$ proteins, ${ }^{18,19}$ static cytometric analyses were performed to study their intracytoplasmic distribution. Intracellular distribution of bcl2 (not shown) and bax (Figure 7a,b) proteins appeared to be very similar between mock-transfected (Figure 7a, CMV2 clone) and vpr-expressing clones (Figure 7b, vpr-4 clone). However, according to quantitative data previously published by our group, ${ }^{1}$ static cytometric evaluation of bax molecule only showed a lower positivity in vpr-transfected cells (compare Figure $7 \mathrm{a}$ and $\mathrm{b}$ which represent control and vpr-expressing cells, respectively). By contrast, an appreciable different arrangement of $\mathrm{bcl}-\mathrm{x}_{\mathrm{L}}$ molecule, known to exert an antiapoptotic activity, was detected in vpr-producing cells (Figure 7d) with respect to control cells
(Figure 7c). In particular, in the vpr-expressing cell cytoplasm, bcl- $\mathrm{x}_{\mathrm{L}}$ protein was organized in a network-like manner to form characteristic filamentous structures (Figure 7d, vpr4 clone). By contrast, punctuate dot spot distribution (probably referred to mitochondria) was mainly detected in mock-transfected clones (Figure 7c, CMV3 clone). A specific quantitative analysis of the intracellular distribution of bcl- $x_{L}$ in different mock-transfected (CMV2, CMV3 and CMV5) and vpr-expressing clones (vpr4, vpr7, vpr9 and vpr10) was thus performed with the aim to evaluate the rate of cells displaying dot-spots or filamentous fluorescent structures. As shown in Figure 7e, significantly different percentages of cells showing filament-like structures or small roundish bodies (resembling small organelles such as mitochondria) were found. High percentages of filamentlike structures were mainly found in vpr-expressing cells (72\%). In addition, after an apoptotic stimulus, e.g. by $\mathrm{CHX} / \mathrm{TN} \alpha$, a re-distribution of $\mathrm{bcl}-\mathrm{x}_{\mathrm{L}}$ molecule clearly occurred. This led to a dot spot positivity also in the majority of vpr-expressing cells (64\%).

\section{Effect of vpr protein on mitochondrial membrane potential homeostasis}

In light of recent data demonstrating that $b c l-x_{L}$ can regulate the homeostasis of mitochondrial membrane potential $(\Delta \psi),{ }^{20}$ we analyzed, by double staining procedure with the JC-1 probe ${ }^{21}$ the $\Delta \psi$ variation during apoptosis in both mock- and vpr-transfected cells. The data obtained (Figure 8) show that, after $\mathrm{CHX}$-TNF- $\alpha$-induced apoptosis, the percentage of cells with depolarized mitochondria was significantly $(P<0.01)$ lower in vpr-expressing clones with respect to mocktransfected cells $(\Delta=56 \%)$. Similar results were obtained inducing apoptosis by using anti-Fas triggering ( $\Delta=62 \%)$.

\section{Discussion}

In this article, we have described cellular and molecular changes, specifically induced by vpr in transfected Jurkat $T$ cells, which may play an important role in the regulation of the apoptotic processes and, more generally, in some pathogenic events occurring in the course of HIV-1 infection. The main results reported in this article can be summarized as follows: (1) vpr-expressing Jurkat cells formed cell clusters with time in culture (without forming syncytia) and the acquisition of this phenotype was specifically mediated by vpr, since it was completely reverted by the addition of AO targeted at vpr; (2) vpr-expressing clones exhibited an increased expression of certain adhesion molecules (i.e., integrins $\alpha 5$ and $\alpha 6$, and cadherin); this was also due to the vpr expression in the transduced cells, since the expression of these surface molecules was reverted to values found in control transduced clones after cell exposure to $\mathrm{AO}$; (3) a significant increase and re-assembly of specific cytoskeleton components (F-actin microfilaments) was consistently detected in vpr-expressing Jurkat cells as compared to mock-transfected clones.

In previous studies, we reported that vpr, expressed at low levels in genetically modified Jurkat cells, acts as a negative regulator of apoptosis. ${ }^{1}$ The present finding that vpr enhances the expression of certain adhesion molecules 
and promotes both cell-to-cell and cell-substrate interaction suggests that low intracellular levels of this viral protein can inhibit apoptosis by mechanisms favoring cell adhesion phenomena. In this regard, it is of interest to mention that recent theories suggest that the 'homeless' condition may lead to cell death by apoptosis ${ }^{22}$ and that this particular type of programmed cell death, i.e. anoikia (from greek: without home), is abolished by the cell homing ability, i.e. cell anchorage. ${ }^{23}$ However, the great majority of studies on apoptosis and cell adhesion have been focused on those

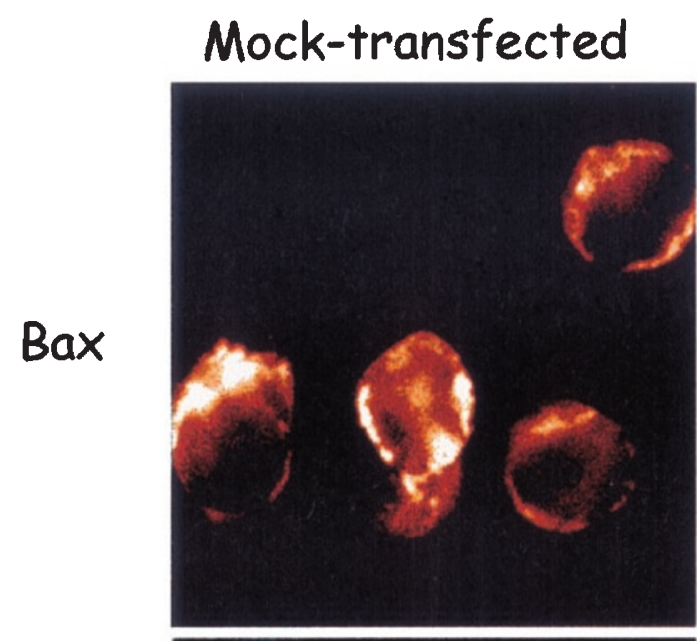

\section{Vpr-transfected}
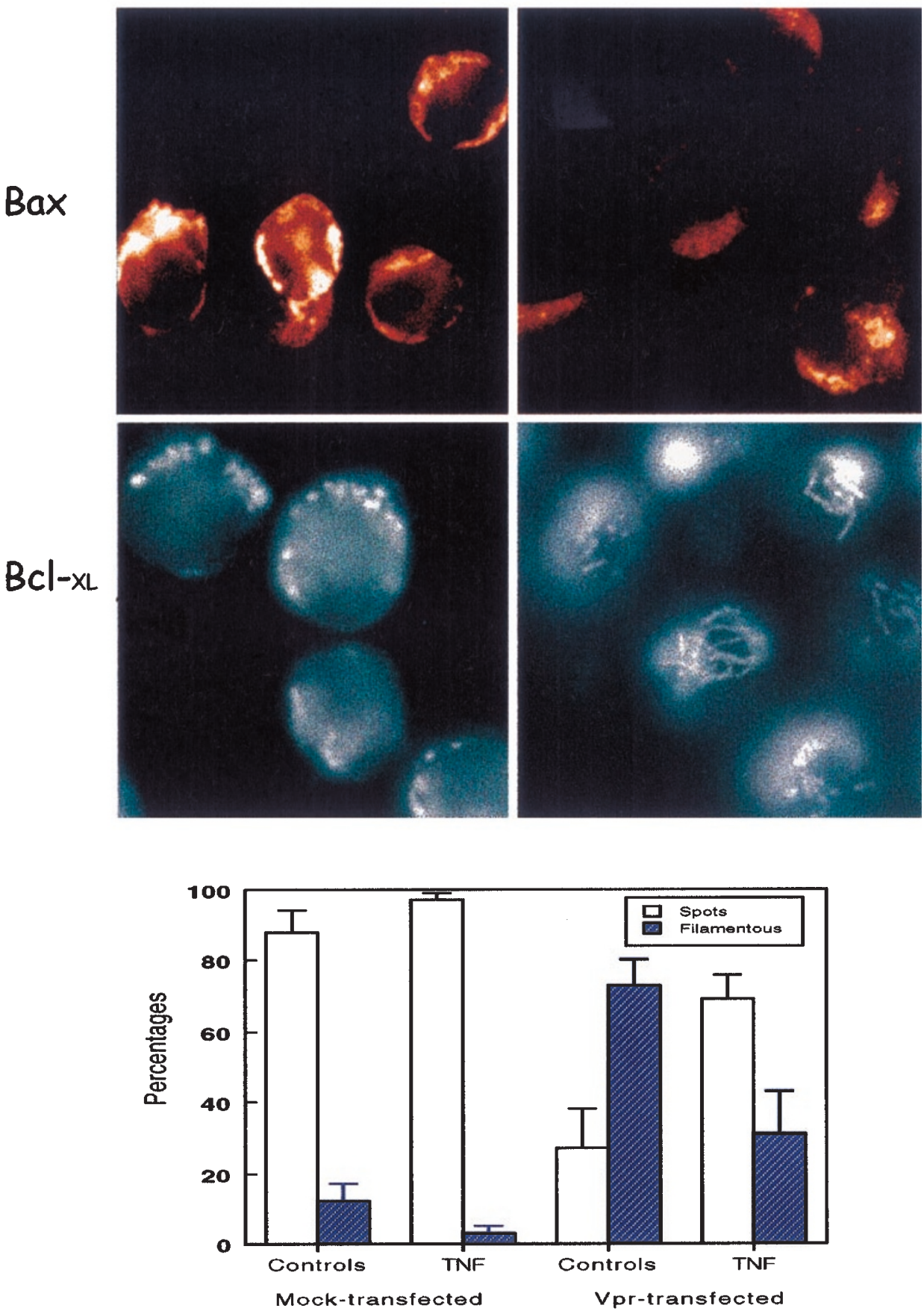

Figure 7 Effects of vpr on bcl- $x_{\llcorner}$intracytoplasmic distribution. (a-d): static cytometry analysis by confocal microscopy of bax $(\mathbf{a}, \mathbf{b})$ and bcl- $\mathrm{x}_{\llcorner}(\mathbf{c}, \mathbf{d})$ in mock- (left panel, CMV3) and vpr-transfected (right panel, vpr4) cells. Magnification $1500 \times$. (e): quantitative analysis (mean values) of bcl- $x_{L}$ intracellular distribution in mock(CMV2, CMV3, CMV5) and vpr-transfected (vpr4, vpr7, vpr9 and vpr10) clones. $\left(^{*}\right)$ in (e) indicates a significant $(P<0.01)$ difference between mock-transfected clones and vpr-expressing cells both before and after treatment with $\mathrm{CHX/TNF-} \alpha$ 


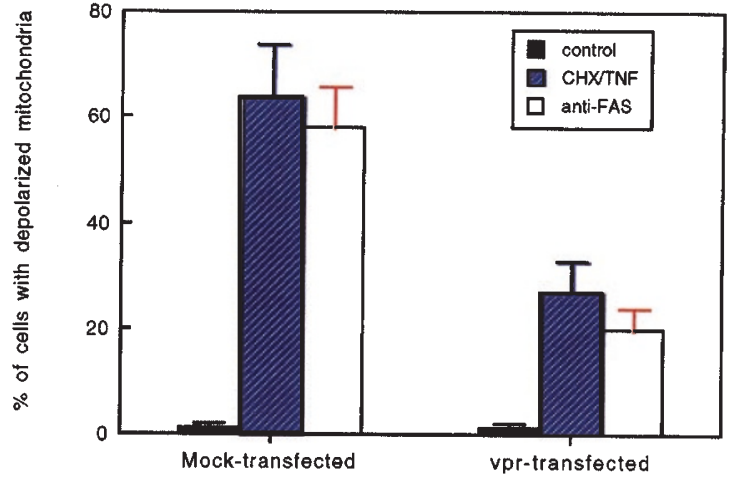

Figure 8 Effect of vpr protein on mitochondrial membrane potential $(\Delta \psi)$. Percentage of cells with depolarized mitochondria as revealed by statistical analysis of the data obtained by flow cytometry after staining with JC-1 probe (as reported in Materials and Methods). Vpr protein offered significant protection to the apoptosis-associated mitochondrial membrane depolarization after both $\mathrm{CHX} / \mathrm{TNF}-\alpha$ treatment and Fas triggering. ${ }^{*}{ }^{*}$ Indicates $P<0.001$ versus mock-transfected cells

mechanisms which control interaction of 'professional' adhering cells, e.g., epithelial and fibroblastic cells, with ECM molecules. In this report we propose to extend the term anoikia to cells whose growth is completely unrelated to substrate adhesion but that are however capable of establishing transient cell-cell and cell-substrate interactions. In fact, the main difference in growth features of mock- and vpr-transfected clones is represented by the increased homotypic interaction detectable by microscopic analyses. Cell-to-cell contacts and intertwining appear clearly enhanced in all vpr-expressing clones. Thus, we suggest that a vpr-induced up-regulation in the expression of a certain set of adhesion molecules (including integrins $\alpha 5$ and $\alpha 6$ and cadherin) could be one of the major events leading to improvement of cell adhesion properties and subsequent resistance to apoptosis.

Cell-to-cell and cell-matrix interactions play a pivotal role in numerous cell functions, such as gene regulation, cytoskeletal assembly and locomotion, differentiation and cell growth control. The extracellular matrix as well as neighboring cells act as survival factors for many cell types. ${ }^{24,25}$ Moreover, lack of matrix attachment could stringently restrict inappropriate cell growth by inducing apoptosis in certain histotypes. ${ }^{9}$ Consequently, an increase in cell adhesion and spreading, a cytoskeleton associated phenomenon, ${ }^{16,26}$ can protect cells against apoptosis. In addition, a specific anti-apoptotic signaling exerted by integrins, particularly $\alpha 5$ and $\alpha 6$, should also be taken into account. In fact, it has been shown that the ligation of these integrins, as well as their over-expression, is associated with inhibition of apoptosis and cell survival. ${ }^{8,27}$ In particular, Zhang and coworkers ${ }^{8}$ first proposed a mechanism showing that integrin $\alpha 5$ was efficient in preventing cell death by regulating the expression of the cell death suppressor bcl-2. Accordingly, we have recently reported that, in epithelial cells, the increased expression of bcl-2 is consistent with the augmented expression of $\alpha 5, \alpha 6$ and cadherin molecules. ${ }^{16}$ Finally, concerning vpr, we have demonstrated that the constitutive expression of this protein in Jurkat $T$ cells resulted in an up-regulation of bcl-2 protein. ${ }^{1}$ Hence, according to other reports, ${ }^{8,28}$ we propose a specific role for integrins as signal transducers in the phenomenon of anoikia. However, the intracellular mechanisms responsible for this activity are currently a matter of debate. ${ }^{29}$

The expression on the cell surface of a plethora of molecules, including cell adhesion molecules, appears to be regulated by the cytoskeletal element integrity and function. ${ }^{10}$ In particular, the microfilament system has been implicated in the up- or down-regulation of some surface molecules (i.e., integrins and immunoglobulin-like molecules) which can be modulated depending on the cell activity. ${ }^{12}$ For instance, it has been suggested that when microfilament system toxicants are employed, a disregulation of surface molecule expression can occur. ${ }^{30}$ In addition, alteration of cytoskeleton integrity can generally influence apoptotic process. ${ }^{12}$ In turn, this could be the consequence of changes in surface molecule expression. ${ }^{13}$ Notably, a close relationship between cadherin overexpression and actin cytoskeleton activity has been suggested. ${ }^{31}$ In this regard, it is of interest to note that the vpr-transfected Jurkat cells exhibited specific quantitative and qualitative modifications of the F-actin content. However, qualitative and quantitative analyses of molecules playing a key role in actin filament assembly and network formation, i.e. actin-binding proteins talin, vinculin, filamin, fodrin, ezrin etc., revealed a significant change only in ezrin content of vpr-expressing clones with respect to mocktransfected cells. This protein, belonging to ERM (ezrinradixin-moesin) family, has a specialized function in lymphocyte migration ${ }^{32}$ and its increase can thus be consistent with the increased expression of $\alpha 5$ and $\alpha 6$ integrins found in vpr-producing cells. Concerning the GTPbinding proteins of the rho family, a statistically significant difference between control and vpr-expressing cells was found. In particular, the rho B isoform, which represents an inducible form of this protein, appeared increased in vprwith respect to mock-transfected cells. However, specific studies are in progress in order to better elucidate the role of the small GTP-binding proteins of the rho family by using specific modulators of their activity. ${ }^{16}$ Thus, on the basis of above results, the effect exerted by vpr, directly and/or indirectly, seems to be due to a 'trophic' activity of this protein on actin microfilament system function. Interestingly, vpr shares sequence similarities with the yeast cytoskeleton protein Sac-1p. ${ }^{33}$ The Sac-1p equivalent has not yet been described in mammalian cells. However, some recent findings point to an actin binding protein implicated in endocytic membrane traffic ${ }^{34}$ (Singer-Kruger et al, 1998). On the other hand, some intriguing results have recently been published showing modifications of the actin cytoskeleton in the $\mathrm{CD}^{+} \mathrm{T}$ lymphocytes from infected patients ${ }^{35}$ or suggesting that some alterations of adhesion molecule expression and increased actin polymerization could play a key role in transendothelial migration. ${ }^{36}$

It is known that vpr protein exhibits the interesting property of being carried into viral particles and plays an important role in the first steps of infection, when the 
regulatory proteins (tat and rev) are not yet present. ${ }^{37}$ Thus, taking into consideration the vpr-induced changes in the Jurkat cell model described in this article and extrapolating their possible significance to an in vivo situation, we may envisage the following scenario: (1) during an acute infection of $\mathrm{CD}^{+} \mathrm{T}$ lymphocytes, the HIV-1 vpr protein may enhance the expression of certain adhesion molecules, possibly through an action on actin cytoskeleton components, recently shown to play a key role in HIV replication. ${ }^{38}$ This event may result in the establishment of tight cell-to-cell and cell-substrate interactions, possibly influencing cell migration, cytoskeleton-dependent syncytia formation $^{39}$ and homing within lymphoid tissues; (2) these events may result in enhanced resistance to apoptosis and persistence of the virus-infected cells, which may represent a specific HIV-1 strategy for protecting its own reproductive 'niche'; (3) HIV-1 can subsequently undergo replication cycles at later stages of the disease, as a result of cell exposure to locally produced activation factors, thus leading to high levels of vpr expression. At later stages of infection, this high vpr expression may contribute to cell growth arrest and apoptosis of infected cells with subsequent spreading of free viral particles or virusinfected cells to other tissues.

\section{Materials and Methods}

\section{Cell cultures}

Mock- and vpr-transfected Jurkat $\mathrm{T}$ cell clones were established as previously described. ${ }^{1}$ Briefly, they have been obtained by seeding Jurkat cells in semi-solid medium soon after transfection of the vprencoding vector, and continuously grown in the presence of G418 to maintain the selective pressure for the expression vector. Moreover, the expression of vpr was routinely checked by RT-PCR. On the basis of their clonal origin, we assume that all cells express vpr. Cells were maintained in RPMI medium (GIBCO Ltd, Paisley, UK) containing $10 \%$ foetal calf serum (FCS, GIBCO) and $500 \mu \mathrm{g} / \mathrm{ml} \mathrm{G}-418$ and periodically controlled for vpr expression.

\section{Inhibition of vpr expression by antisense phosphorothioate oligodeoxynucleotides}

Vpr-expressing clones were treated with antisense phosphorothioate oligodeoxynucleotides $(\mathrm{AO})$ targeted at the open reading frame of $\mathrm{vpr}$ as previously described. ${ }^{40}$ In brief, cells seeded at the concentration of $5 \times 10^{5} / \mathrm{ml}$ were treated with $15 \mu \mathrm{M}$ of either $\mathrm{AO}$ (oligonucleotide 3 ) or control sense (SO, oligonucleotide 4) every $24 \mathrm{~h}$.

\section{Morphometric analyses}

In order to quantitatively evaluate cell-cell adhesion, (i) the number of cell clusters as well as (ii) the amount of cells aggregated to form clusters have been considered. In fact, different aggregates formed by few or many cells, i.e. smaller or larger, were found. In consideration of this size variety, we arbitrarily defined eight different classes, from single cells to clusters formed by more than 50 cells, and we analyzed cell distribution in mock-transfected and vpr-expressing clones. These analyses were performed in the presence or in the absence of either $\mathrm{AO}$ or control SO, as described above. For the quantification of data regarding both cell-cell adhesion (Figure 2 ) and bcl- $x_{\mathrm{L}}$ intracytoplasmic distribution (Figure 7e), at least 50 microscopic fields, for a total amount of 500 cells, were counted in quadruplicate at high magnification $(500 \times)$ by a phase contrast microscope.

\section{Scanning electron microscopy (SEM)}

Cells were fixed with $2.5 \%$ glutaraldehyde in $0.1 \mathrm{M}$ cacodylate buffer ( $\mathrm{pH} \mathrm{7.4)} \mathrm{at} \mathrm{room} \mathrm{temperature} \mathrm{for} 20 \mathrm{~min}$. Following post-fixation in $1 \%$ $\mathrm{OsO}_{4}$ for $30 \mathrm{~min}$, cells were dehydrated through graded ethanol, critical point dried in $\mathrm{CO}_{2}$ and gold coated by sputtering. The samples were examined by a Cambridge 360 scanning electron microscope.

\section{Adhesion assay}

Stock preparations of fibronectin and laminin were distributed in 24well plates at the final concentrations of 5 and $2 \mu \mathrm{g} / \mathrm{cm}^{2}$, respectively. After $2 \mathrm{~h}$ at room temperature, the coated dishes were washed three times with PBS to remove non-immobilized proteins. To saturate non specific protein binding sites, $2 \mathrm{ml}$ of PBS supplemented with $1 \%$ heatdenatured BSA were added and the plates were incubated at room temperature for $1 \mathrm{~h}$. Cells were then seeded in the coated 24-well plates at the concentration of $10^{5}$ cells per well and incubated at $37^{\circ} \mathrm{C}$ for $2 \mathrm{~h}$. As positive control, wells coated with poly-L-lysine $(1 \mathrm{mg} / \mathrm{ml})$ were used. The attachment assay was adapted from that described elsewhere. $^{4}$

\section{Induction and evaluation of apoptosis}

Cells were induced to undergo apoptosis by a combined treatment with cycloheximide (CHX) and tumor necrosis factor- $\alpha$ (TNF- $\alpha)$ or by antiFas antibody. In the first the cells were treated with $4 \mu \mathrm{M} \mathrm{CHX}$ (Sigma Chemicals Co. St Louis, MO, USA) for $2 \mathrm{~h}$. After this time, $50 \mathrm{IU} / \mathrm{ml}$ TNF- $\alpha$ (Sigma, final purity $>95 \%$ ) were added to the cultures for a further $2 \mathrm{~h}$. Cells treated with either CHX or TNF- $\alpha$ alone for $4 \mathrm{~h}$ were used as additional control. For Fas triggering, cells were treated for $4 \mathrm{~h}$ with $50 \mathrm{ng} / \mathrm{ml}$ of an antibody to Fas (IgM; Chemicon International, Inc., Temecule, CA, USA). The extent of apoptosis was evaluated by both microscopic and flow cytometry analyses. The chromatin dye Hoechst 33258 (Molecular Probes Inc. Eugene, OR, USA) was used to visualize chromatin condensation and clumping as described elsewhere. ${ }^{42}$ Quantitative evaluation of apoptotic cells was performed by counting at least 12 microscopic fields in quadruplicate for a total amount of at least 500 cells at high magnification $(500 \times)$ in a Nikon Microphot fluorescence microscope. Apoptosis was detected by using the following flow cytometry methods: (i) decreased DNA content (subdiploid peak characteristic of DNA fragmentation) by using propidium iodide staining (PI, Molecular Probes); (ii) TUNEL method (Boehringer Mannheim, Milan, Italy) detects TdT incorporation of labeled nucleotides into DNA strand breaks and (iii) Annexin V-FITC (Eppendorf Mi, Italy) detection is based on the observation that soon after initiating apoptosis most cell types translocate the membrane phospholipid phosphatidylserine from the inner face of the plasma membrane to the cell surface. This reaction can be directly performed on living cells, without fixation. Injured and dead cells were excluded by using PI (Molecular Probes). Samples were then analyzed by a FACScan flow cytometer from Becton Dickinson (San José, CA, USA) equipped with a $488 \mathrm{~nm}$ argon laser. Data were recovered by a Hewlett Packard computer using the Lysys II Software.

\section{Analytical cytology of adhesion molecules and cytoskeletal proteins}

For detection of intracellular antigens, cells were pelleted, fixed in $70 \%$ ice-cold methanol and washed twice with cold PBS before labeling. 
We used monoclonal antibodies (MAbs) for the detection of: cadherin (anti-pan-cadherin, Sigma), $\alpha$-actinin (Chemicon), gelsolin (Chemicon), talin (Chemicon), vinculin (Chemicon), ezrin (Chemicon), filamin (Chemicon), and $\alpha / \beta$ tubulin (Sigma). We used polyclonal antibodies (PAbs) for the detection of fodrin (Sigma). Cells were incubated for $1 \mathrm{~h}$ at $4^{\circ} \mathrm{C}$ then washed and further incubated for $30 \mathrm{~min}$ at $37^{\circ} \mathrm{C}$ with FITC-labeled anti-mouse MAb (Sigma) or anti-rabbit PAb (Sigma), washed again and analyzed by flow and static cytometry. For detection of surface molecules, cells were incubated for $30 \mathrm{~min}$ at $4^{\circ} \mathrm{C}$ with specific MAbs (Chemicon) to ICAM-1 (CD54), CD44, $\alpha 1$ (CD49a), $\alpha 2$ (CD49b), $\alpha 3$ (CD49c), $\alpha 4$ (CD49d), $\alpha 5$ (CD49e), $\alpha 6$ (CD49f), $\alpha$ v (CD51) and $\beta 1$ (CD29). After washings with ice-cold PBS containing $10 \mathrm{mM}$ $\mathrm{NaN}_{3}, 1 \%$ BSA (Sigma) and $0.002 \%$ ethylenediamine tetraacetate (EDTA), cells were incubated for 30 min at $4^{\circ} \mathrm{C}$ with FITC-labeled antimouse MAb (Sigma) and washed. Cell viability was checked by adding samples with $\mathrm{PI}(10 \mu \mathrm{g} / \mathrm{ml})$ followed by their immediate analysis by a Hewlett Packard computer using the Lysys II software (Becton Dickinson).

\section{Evaluation of microfilament system organization}

Cells were fixed with $3.7 \%$ formaldehyde in phosphate buffered saline (PBS) with $2 \%$ bovine serum albumin (BSA), for $10 \mathrm{~min}$ at room temperature. After washing in the same buffer, cells were permeated with $0.5 \%$ Triton $\mathrm{X}-100$ in PBS for 10 min at room temperature. For Factin and G-actin detection, cells were stained at $37^{\circ} \mathrm{C}$ for 30 min with FITC-phalloidin (Sigma), or FITC-DNase I, respectively. ${ }^{43}$ For detection of the total amount $(F+G)$ of actin, cells were incubated with an antibody to actin (MAb, Chemicon) for $1 \mathrm{~h}$ at $4^{\circ} \mathrm{C}$ and, after washings, with FITC-labeled anti-mouse MAb (Sigma) for $30 \mathrm{~min}$ at $37^{\circ} \mathrm{C}$. Finally, after washings, cells were analyzed by a flow cytometer (Becton Dickinson) or observed by using both conventional fluorescence microscopy (Nikon Microphot) and as showed in Figure $6 b, c$, lines 1, 2 and 3.

\section{Analytical cytology of bcl-2 family proteins}

To quantitatively and qualitatively evaluate $b c l-2, b c l-x_{L}$ and $b a x$ proteins control and vpr transfected Jurkat cells were pelleted, fixed in $70 \%$ ice-cold methanol, and washed twice with cold PBS. For bax and $\mathrm{bcl}-\mathrm{x}_{\mathrm{L}}$ detection, cells were stained for $1 \mathrm{~h}$ at $4^{\circ} \mathrm{C}$ with PAbs (Santa Cruz Biotechnology Inc. CA, USA). After washing, cells were incubated for $30 \mathrm{~min}$ at $37^{\circ} \mathrm{C}$ with FITC-labeled PAb anti-rabbit (Sigma). For the detection of bcl-2, cells were stained with a MAb FITC-labeled anti-bcl-2 (Dako S.p.A, MI, USA) at a final concentration of $0.1 \mu \mathrm{g} / \mathrm{ml}$ for $30 \mathrm{~min}$ at $4^{\circ} \mathrm{C}$. After washing all samples were immediately analyzed by a flow cytometer or by fluorescence (Nikon Microphot) or confocal scanning laser microscopy (Molecular Dinamics Sarastro 2000). The acquisitions were recorded employing the pseudo-colors.

\section{Analysis of mitochondrial membrane potential $(\Delta \psi)$}

$\Delta \psi$ was studied in Jurkat cells by using $10 \mu \mathrm{g} / \mathrm{ml}$ of $5,5^{\prime}, 6,6^{\prime}$ tetrachloro-1, $1^{\prime}, 3,3^{\prime}$-tetraethylbenzimidazol-carbocyanine iodide (JC1, Molecular Probes) as previously described. ${ }^{21} \mathrm{JC}-1$ is a molecule able to selectively enter mitochondria, and exists in monomeric form emitting at $527 \mathrm{~nm}$ after excitation at $488 \mathrm{~nm}$. However, depending on the membrane potential, JC-1 can form J-aggregates that are associated with a large shift in the emission $(590 \mathrm{~nm})$, and can be easily detected in the orange channel (FL2). JC-1 is both qualitative (considering the shift from green to orange JC-1 fluorescence emission) and quantitative (considering the pure fluorescence intensity, which can be detected in both FL1 and FL2 channels). After washing with cold PBS, samples were immediately analyzed on a FACScan flow cytometer (Becton Dickinson, San José, USA) equipped with a $488 \mathrm{~nm}$ argon laser. Quantification of the data obtained (reported in Figure 8) was performed by a Hewlett Packard computer using the Lysys II software (Becton Dickinson).

\section{Statistical analyses}

All values reported in this paper are given as mean value \pm S.D. from four or more separate experiments performed in quadruplicate. Values reported in Figures 2, 4, 7 and 8 represent the mean value obtained among three CMV clones (CMV2, CMV3 and CMV5) and four vpr positive clones (vpr4, vpr7, vpr9 and vpr10). Student's $t$-test ('statistics' program for Macintosh) for correlated samples was used. A $P$ value of less than 0.01 was considered significant. Concerning flow cytometry, the statistical significance of the values obtained, reported in Tables 1 and 2, was calculated by using the KolmogorovSmirnov (K/S) test included in Lysys II software (Becton Dickinson). Asterisks in Tables 1 and 2 indicate antigens which undergo significant quantitative variation in vpr- with respect to mock-transfected clones. Manova test was performed, by using SAS program for Macintosh, to evaluate differences among distribution curves of cell clusters (Figure 2) and rho family proteins (Table 2 ).

\section{Acknowledgements}

This work was partially supported by X and XI AIDS Project to W Malorni and $\mathrm{F}$ Belardelli. We thank Mrs Maria Letizia Semeraro and Mr Marco Sabatini for their helpful technical assistance.

\section{References}

1. Conti L, Rainaldi G, Matarrese P, Varano B, Rivabene R, Columba S, Sato A, Belardelli F, Malorni W and Gessani S (1998) The HIV-1 protein acts as a negative regulator of apoptosis in a human lymphoblastoid T cell line: possible implications for the pathogenesis of AIDS. J. Exp. Med. 187: 403-413

2. Cohen EA, Dehni G, Sodroski JG and Haseltine WA (1990) Human immunodeficiency virus vpr product is a virion-associated regulatory protein. J. Virol. 64: 3097-3099

3. Checroune F, Yao XJ, Gottlinger HG, Bergeron D and Cohen EA (1995) Incorporation of vpr into human immunodeficiency virus type 1: role of conserved regions within the p6 domain of Pr55gag. J. Acquired Immune Defic. Syndr. 10: $1-7$

4. Ayyavoo V, Mahaboubi A, Ramalingam R, Kudchodkar S, Williams WV, Green DR and Weiner DB (1997) HIV-1 vpr suppresses immune activation and apoptosis through regulation of nuclear factor kB. Nat. Med. 3: 1117-1123

5. Stewart SA, Poon B, JowettJBM and Chen ISY (1997) Human immunodeficiency virus type 1 induces apoptosis following cell cycle arrest. J. Virol. 71:5579-5592

6. Shen Y and Schenk TE (1995) Viruses and apoptosis. Curr. Opin. Genet. Dev. 5: $105-111$

7. Fukumori T, Akari H, FidaS, Hata S, Kagawa S, Aida Y, Koyama AHand Adachi A (1998) The HIV-1 vpr displays strong anti-apoptotic activity. FEBS Lett. 432: 1720

8. Zhang Z, Vuori K, Reed JC and Ruoslahti E (1995) The $\alpha 5 \beta 1$ integrin supports survival of cells on fibronectin and up-regulated Bcl-2 expression. Proc. Natl. Acad. Sci. USA 92: 6161-6165

9. Ruoslahti E and Reed JC (1994) Anchorage dependence, integrins, and apoptosis. Cell 77: 477-478

10. Sheetz MP, Felsenfeld DP and Gallabraith CG (1998) Cell migration: regulation of force on extracellular-matrix-integrin complexes. Trends Cell Biol. 8: 51-54

11. Small JV, Rottner K, Kaverina I and Anderon KI (1998) Assembling an actin cytoskeleton for cell attachment and movement. Biochim. Biophys. Acta. 1404: $271-281$ 
12. Janmey PA (1998) The cytoskeleton and cell signaling: component localization and mechanical coupling. Physiol. Rev. 78: 763-781

13. Vitale M, Di Matola T, Fenzi G, Ilario Mand Rossi G (1998) Fibronectin is required to prevent thyroid cell apoptosis through an integrin-mediated adhesion mechanism. J. Clin. Endocrinol. Metab. 83: 3673-3680

14. Meredith Jr JE and Schwartz MA (1997) Integrins, adhesion and apoptosis. Trends Cell. Biol. 7: 146-150

15. Kumar CC (1998) Signaling by integrin receptor. Oncogene 17: 1365-1373

16. Fiorentini $C$, Matarrese $P$, Straface E, Falzano L, Donelli G, Boquet $P$ and Malorn W (1998) Rho-dependent cell spreading activated by E. Coli cytotoxic necrotizing factor 1 hinders apoptosis in epithelial cells. Cell Death Differ. 5 921-929

17. Gomez J, Martinez C, Giry M, Garcia A and Rebollo A (1997) Rho prevents apoptosis through $\mathrm{Bcl}$-2 expression: implication for interleukin 2-receptor signa transduction. Eur. J. Immunol. 27: 2793-2799

18. Abbracchio MP, Rainaldi G, Giammarioli AM, Ceruti S, Brambilla R, Cattabeni F, Barbieri D, Franceschi C, Kenneth AJ and Malorni W (1997) The $A_{3}$ adenosine receptor mediates cell spreading, reorganization of actin cytoskeleton, and distribution of Bcl- $\mathrm{x}_{\mathrm{L}}$ : studies in human astroglioma cells. Biochem. Biophys. Res. Commun. 241: 297-304

19. Wolter KG, Hsu YT, Smith CL, Nechushtan A, Xi XG and Youle RJ (1997) Movement of Bax from the cytosol to mitochondria during apoptosis. J. Cell Biol. 139: $1281-1292$

20. Vender Heiden MG, Chandel NS, Williamson EK, Schumacker PT and Thompson CB (1997) Bcl-xL regulates the membrane potential and volume homeostasis of mitochondria. Cell 91:627-637

21. Cossarizza A, Franceschi C, Monti D, Salvioli S, Bellesia E, Rivabene R, Biondo L, Rainaldi G, Tinari A and Malorni W (1995) Protective effect of N-acetylcysteine in Tumor Necrosis Factor alpha-induced apoptosis in U937 cells: the role of mitochondria. Exp. Cell Res. 220: 232-240

22. Valentinis B, Reiss Kand Baserga R (1998) Insulin-like growth factor-I-mediated survival from anoikis: role of cell aggregation and focal adhesion kinase. J. Cell. Physiol. 176: 684-657

23. Frisch SM and Francis H (1994) Disruption of epithelial cell-matrix interactions induce apoptosis. J. Cell Biol. 124: 619-626

24. O'Brien V, Frisch SM and Juliano RL (1996) Expression of the integrin alpha 5 subunit in HT29 colon carcinoma cells suppresses apoptosis triggering by serum deprivation. Exp. Cell Res. 224: 208-213

25. Kantak SS and Kramer RH(1998) E-cadherin regulates anchorage-independent growth and survival in oral squamous cell carinoma. J. Biol. Chem. 273: 1695316961

26. Ruoslahti $E$ (1997) Stretching is good for a cell. Science 276: 1345-1346

27. van Kooyk Y, Lub M and Figdor CG (1998) Adhesion and signaling mediated by the cytoplasmic tails leukocyte integrins. Cell. Adhes. Commun. 6: 247-254

28. Levkau B, Herren B, Koyama H, Ross R and Raines EW (1998) Caspasemediated cleavage of focal adhesion kinase $\mathrm{pp}^{125}$ FAK and disassembly of foca adhesion in human endothelial cell apoptosis. J. Exp. Med. 187: 579-586
29. Delcommenne M, Tan C, Gray V, Rue L, Woodgett J and Dedhar S (1998) Phosphoinositide-3-OH kinase-dependent regulation of glycogen synthase kinase 3 and protein kinase B/AKT by integrin-linked kinase. Proc. Natl. Acad. Sci. USA 95: $11211-11216$

30. Nobes CD, Lauritzen I, Mattei MG, Paris S, Hall A and Chardin P (1998) A new member of the Rho family, Rnd1, promotes disassembly of actin filament structures and loss of cell adhesion. J. Cell. Biol. 141: 187-197

31. Hazan RB and Norton L (1998) The epidermal growth factor receptor modulates the interaction of E-cadherin with the actin cytoskeleton. J. Biol. Chem. 273: 9078-9084

32. Serrador JM, Nieto Mand Sanchez-MadridF (1999) Cytoskeletal rearrangement during migration and activation of T lymphocytes. Trends Cell Biol. 9: 228-232

33. Cleves AE, Novick PJ and Bankaitis VA (1989) Mutations in the Sac1 gene suppress defects in yeast Golgi and yeast actin function. J. Cell. Biol. 109:29392950

34. Singer-Kruger B, Nemoto Y, Daniell L, Ferro-Novick S and De Camilli P (1998) Synaptojanin family members are implicated in endocytic membrane traffic in yeast. J. Cell Sci. 111: $3347-3356$

35. Malorni W, Ribabene R, Lucia BM, Ferrara R, Anna M, Mazzone AM, Cauda R and Paganelli $R$ (1998) Oxidative imbalance in progression to AIDS: another push towards the use of the thiol supplier N-acetyl-cysteine. AIDS Res \& Human Retrovirus 14: $1589-1596$

36. Elbim C, Pillet S, Prevost MH, Preira A, Girard PM, Rogine N, Matusani H, Hakim J, Israel N, Gougerot-Pocidalo MA (1999) Redox and activation status of monocytes from human immunodeficiency virus-infected patients: relationship with viral load. J. Virol. 73: $4561-4566$

37. Cullen BR (1998) HIV-1 auxiliary proteins: making connections in a dying cell. Cell 93: 695-692

38. Bukrinskaya A, BrichacekB, Mann A and Stevenson M(1998) Establishment of a functional human immunodeficiency virus type 1 (HIV-1) reverse transcription complex involves the cytoskeleton. J. Exp. Med. 188: 2113-2125

39. Soll DR (1997) Researchers in cell motility and the cytoskeleton can play major roles in understanding AIDS. Cell Motil. Cytoskel. 37: $91-97$

40. Balotta C, Lusso P, Cowley R, Gallo RC and Franchini G (1993) Antisense phosphorothioate oligodeoxynucleotide target to the vpr gene inhibit human immunodeficiency virus type 1 replication in primary human macrophages. J. Virol. 67: 4409-4419

41. Malorni W, Rivabene R and Matarrese P (1995) The antioxidant N-acetylcysteine protects cultured cells from menadione-induced cytopathology. Chem. Biol. Interact. 96: 113-123

42. Malorni W, Rivabene R, Santini MT and Donelli G (1993) N-acetylcysteine inhibits apoptosis and decreases viral particles in HIV-chronically infected U937 cells. FEBS Lett. 327: 75-78

43. Fiorentini C, Donelli G, Matarrese P, Fabbri A, Paradisi S and Boquet P (1993) Escherichia coli Cytotoxic necrotizing factor 1: evidence for induction of actin assembly by constitutive activation of the p21 Rho GTPase. Infect. Immun. 63: $3936-3944$ 